\title{
Optimization of gas Turbine Filtration System based on Life Cycle Cost (LCC) Theory
}

\author{
Li Xueyu ${ }^{\mathrm{a}}$, Tian Xin ${ }^{\mathrm{b}}$ \\ HuaDian Electric Power Research Institute, NO.2 Xiyuan 9 Road, HangZhou, 310030, China \\ a75061908@qq.com, b453645372@qq.com
}

\begin{abstract}
Keywords: Gas Turbine; Air Intake System; Filtration Elements; Parameters Optimization; LCC Abstract. Air intake system is frequently required to replace filter unit, resulting in high operation and maintenance cost, which can be attributed to the failure to fully take account of the domestic air quality. Based on real power plant operational data, a mathematical model was built to analyze the life cycle cost (LCC). A new method was proposed to optimize the capacity expansion factor $k$ to achieve the lowest LCC. Calculation for F-class combined cycle gas turbine power station shows that in the case of $4500 \mathrm{~h}$ with design life of 30 years, if the initial investment of the air intake system is increased by 5.76 million Yuan, 988,300 Yuan can be saved. The proposed method could have important reference value for the design and selection of appropriate air intake system for new power plants.
\end{abstract}

\section{Introduction}

Air intake system plays an important protective effect in gas turbine passage parts $[1,2,3,4,5]$, currently gets attention by the equipment manufacturers and users because of its high maintenance. As the filter system design usually comes from the OEM manufacturers, the design process lacks of the corresponding analysis of the real domestic condition and running state. What's more, gas turbine filter system is always a lack of systematic research results that the air intake system which performed well in a foreign country but in the domestic frequently appeared not the same and brought a lot of unnecessary operation maintenance cost. A large number of operating experience shows that the cost of air intake system filter replacement is often more than the initial acquisition of filtering system. So it's necessary to analyze the various cost of air intake system life cycle for guiding the production.

Some scholars such as Chen Jianhong have carried on the related research of air intake system filter counter blowing cycle and compressor washing frequency, and put forward the relationship between air intake system filter replacement and washing frequency, and analyze the coping strategies in different boundary conditions[6,7].Aim at KM-81D type air filter of GT13E2 gas turbine, Yang Jiaji builds relationship modeling between time and differential pressure, and studies the optimal replacement cycle of the same category gas turbine filter through the filter pressure difference, gas turbine output and heat consumption rate[8]. Zhu Jinjie expanse the filter of a certain Beijing power plant, increases the level leading to improve the reliability and efficiency, and has made the economy analysis before and after the reconstruction [9]. The above works analyze the influence of intake system on unit performance from different viewpoints so that the air intake system gets better economy in the case of air intake system capacity increasing. But the above researches have not yet optimized according to the actual operation data before the air intake system expansion.

The whole equipment life cycle cost management, short for the LCC management, is the international frontier and popular equipment cost management theory. Its basic meaning is to minimum the whole life cycle cost on the basis of reliability requirements. LCC management includes of the equipment or system design, selection, procurement, operation, maintenance, renovation and retirement, etc in the whole life cycle management. Its core content is analyzing and decision-making on operation life cycle cost of equipment, project or system. Currently the abroad has applied the LCC analysis on the different stages of the electric power industry [10,11,12,13]. And among the domestic researches application of the whole equipment life cycle in power system, the application of grid side research is relatively mature, of which the most use of substation maintenance is typical $[14,15,16]$. 
Based on the air intake system operation data of a certain power plant, this paper analyzes filter element characteristics, and proposes a new kind LCC optimal method according to the air intake system LCC theory. By introducing a filtering system expansion factor $\mathrm{k}$, makes the net present value (NPV) of air intake system minimum in the whole life cycle.

\section{Air intake system LCC analysis principle}

\section{The definition of whole life cycle cost}

The current each kind of literature on the definition of LCC mainly comes from the international electro technical commission standard IEC60300-3-3. The provisions specifies that he equipment life cycle mainly includes the product designing research and development, manufacture, installation and commissioning, operation, maintenance and scrap process. All the cost of relevant process calls whole life cycle cost.

For equipment, the life cycle cost can be expressed by the following relations:

$$
\mathrm{LCC}=\mathrm{C}_{\mathrm{aq}}+\mathrm{C}_{\mathrm{ow}}+\mathrm{C}_{\mathrm{di}}
$$

Among them: $\mathrm{C}_{\mathrm{aq}}$ for the equipment acquisition cost; $\mathrm{C}_{\mathrm{ow}}$ for the equipment ownership cost, usually including operation and maintenance costs; $\mathrm{C}_{\mathrm{di}}$ for equipment disposal cost, usually including waste cost and salvage value. For gas turbine inlet system, the proportion of $\mathrm{C}_{\mathrm{aq}}$ in LCC gradually decreases over time; the proportion of $\mathrm{C}_{\mathrm{ow}}$ gradually rises. Based on the previous engineering experience, $\mathrm{C}_{\mathrm{di}}$ is relatively stable and the proportion is very small, even can be ignored in some cases.

\section{Analysis steps of air intake system LCC}

In IEC60300-3-3, the LCC usually is analyzed and decomposed into the following six stages, shown as figure 1.

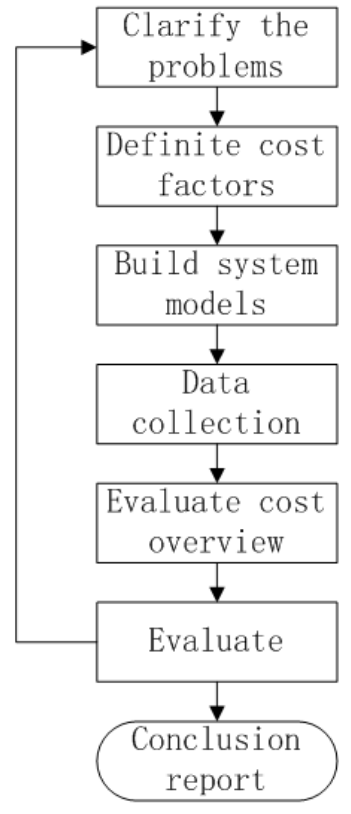

Fig. 1 LCC flow chart

Usually, the first step of LCC cost analysis is to clarify problems. LCC model largely depends on the scope where the model covered and the specific functions which need to implement. So it should be first to determine the operation equipments and maintenance strategy. Cost factors are an important part of LCC model. It's necessary to determine a system to prevent some important cost factors form being ignored. While establishing a breakdown structure of cost model is a good way to solve this problem. And generally the product life cost at different times could be the breakdown structure of cost model. After determining cost factors, it needs to properly reflect the relationship between them in the model of the system. For example, it should be properly considering the analysis reliability, availability and maintainability, etc. As the accuracy of the data directly determines the LCC analysis results reliability, in this paper the data for LCC analysis come from the questionnaire, cost reports, 
historical data records and related contracts. In addition some other data is based on experience and related parameter analysis.

\section{Air intake system LCC model}

According to the experience of many projects, in the service life of gas turbine inlet system, corresponding to IEC60300-3-3 its main fee can be expressed by formula (2), which $\mathrm{LCC}_{\mathrm{ft}}$ is the whole life cycle cost of air intake system.

$$
\mathrm{LCC}_{\mathrm{ft}}=\mathrm{C}_{\mathrm{aq}}+\mathrm{C}_{\mathrm{ow}}+\mathrm{C}_{\mathrm{di}}
$$

Due to the gas turbine intake system actual operation results have great relevance with the area environment, such as the particulate matter pollution degree, the annual average temperature and humidity, the adopted filtering equipment form and etc. So the filter test results in the laboratory often pay more attention on filter rating standards so it can't simulate well the working condition of gas turbine field. At the same time, as for the testing standards, in domestic there is no guidance documents for gas turbine air filter [17], usually the test results can not reflect real filtration efficiency well. So based on actual operation data in the power plant, this paper analyze the characteristic between time and differential pressure, and the characteristic between flow rate and pressure differential of filtering unit (known as the "filter element"). Then establish the mathematical model of a single element, optimize the number sets of filter to get the LCC model of the air intake system.

\section{The acquisition cost of air intake system Caq}

In this paper the optimized parameter is the for impact of air intake system filter logarithmic on the whole life cycle of air intake system, so the acquisition cost of air intake system is expressed in the following relationship.

$$
\mathrm{C}_{\mathrm{aq}}=\mathrm{C}_{\mathrm{st}}+\mathrm{C}_{\mathrm{ft}}
$$

Among them, $\mathrm{C}_{\mathrm{st}}$ for the investment of air intake system holder, filter room and air intake pipe, which is a one-time investment in the air intake system life period. $\mathrm{C}_{\mathrm{ft}}$ for the initial acquisition cost of filter element. As a wearing part, after achieving the gas turbine differential pressure set point, it will be replaced.

In the current acquisition of air intake system, air intake stent is given priority to steel structure, so that the purchasing cost is approximatively proportional to the bracket weight. Under normal circumstances, if the overall structures of the air intake system don't have special big change, the cost caused by intake stents become smaller. Filter room and air intake pipe is directly related to the installation area. In the optimization of filter element number, the air intake pipe can keep the original design due to the unchanged total flow of air intake system, while the filter room will have a certain cost change because of the filter element number changing.

\section{The ownership cost of air intake system $\mathrm{C}_{\mathrm{ow}}$}

In the gas turbine air intake system using process, the biggest cost usually comes from the air filter element replacement. Secondly, in the filter element using process, the new replacement filter filtration ability often needs to be tested. So the ownership cost of air intake system can be expressed by the following formula:

$$
\mathrm{C}_{\mathrm{ow}}=\mathrm{C}_{\mathrm{ch}}+\mathrm{C}_{\mathrm{ma}}
$$

Among them, $\mathrm{C}_{\mathrm{ch}}$ for air intake system filter replacement cost. The practice has proved that this part of the main cost after gas turbine air intake system using. The domestic air intake system using situation in gas turbine power generation enterprise shows that most of the filter element service life cannot reach $8000 \mathrm{~h}$ to $12000 \mathrm{~h}$. As in the current domestic process of design and procurement, the consideration of domestic specific environmental factors is relatively small. Even in some bad weather area, the gas turbine filter element will have to be replaced after running from $2000 \mathrm{~h}$ to $3000 \mathrm{~h}$. $\mathrm{C}_{\mathrm{ma}}$ for filter element using cost. This part mainly contains the operation maintenance cost in the filtration system using process, and the additional fuel cost caused by the heat loss rate changing. 
On the basis of the gas turbine operation maintenance experience, many scholars studied $\mathrm{C}_{\text {ma }}$. Cyrus B. Meher Homji studied the influence of air compressor fouling for gas turbine efficiency, the heat consumption rate and emissions [19]. Melissa Wilcox systematically elaborated gas turbine air intake system LCC, and summarized the running and maintenance costs [20]. With the rapid growth of domestic gas turbine design, and gradually attention on the gas turbine supervision work form gas turbine power generation group, filter detection has become normal. In the model of this paper, the experiment cost is the sampling test cost of each batch filter element.

\section{The disposal cost of air intake system}

During the using process of gas turbine air intake system, the biggest cost usually comes from the air intake filter element replacement. Secondly, in the using process of the filter element, the filtration ability of new replacement filter will be often test. So the ownership cost of air intake system can be expressed by the following formula:

$C_{d i}=-C_{\mathrm{sv}}$

Among them, $\mathrm{C}_{\mathrm{sv}}$ for the equipment scrap value.

\section{The LCC analysis and optimization of air intake system in a certain power plant}

\section{Characteristic analysis of air intake filter element}

An F-class combined cycle gas turbine power station uses Donaldson self-cleaning filtering system. This system adopts two stage series filter with the air filter quantity of $389400 \mathrm{~kg} / \mathrm{h}$. The first filter is 165 groups of G4 static filter, and the alarm value of differential pressure is $0.25 \mathrm{kPa}$. The second filter is 900 groups of F8 self-cleaning filter, and the alarm value of differential pressure is $0.9 \mathrm{kPa}$. Assuming each filter unit with uniform air intake, because all the filter units at all levels adopt the parallel arrangement, the differential pressure of the single filter is equal to the level of filter in each level.

Figure 2 shows the differential pressure changing relationship along with running time between the pre-filter and efficient filter of the air intake system. Because the filter system adopts the pre-filter, the unit efficient filter usually replace during running hour from $6500 \mathrm{~h}$ to $6500 \mathrm{~h}$. Comparing with the same area of $3000 \mathrm{~h}$ replacement cycle, this type filter has significant efficiency.

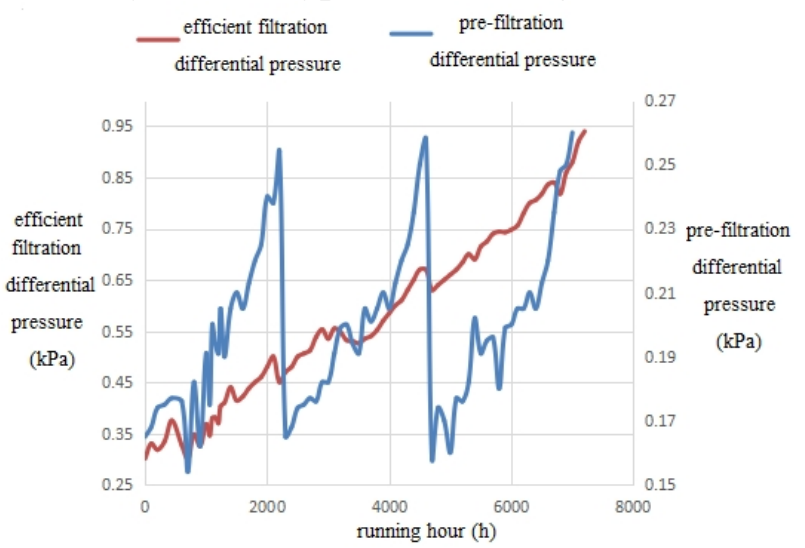

Fig.2 The relation between the differential pressure and the running hours of the pre-filter and the efficient filter

From the filter differential pressure changing relationship, when the pre-filtration and efficient filtration is close to their life cycle in using process, the growth trend of differential pressure in the late period will accelerate due to the dust filter. But on the whole the change is not obvious so it can approximate thought that each level differential pressure of the two-stage filter change linearly with the running time, and the efficient filtration differential pressure change rate is not affected by the prior level differential pressure changes. Then the coarse filtration and efficient filtration differential pressure along with the running time can be expressed by the following relation.

$$
\mathrm{P}_{\mathrm{p}-\mathrm{t}}=0.16+3.91 \times 10^{-5} \mathrm{t}_{1} \quad\left(0 \leq \mathrm{t}_{1} \leq 2300\right)
$$




$$
\mathrm{P}_{\mathrm{e}-\mathrm{t}}=0.29+8.71 \times 10^{-5} \mathrm{t}_{2} \quad\left(0 \leq \mathrm{t}_{2} \leq 7200\right)
$$

Among them, Pp-t and Pe-t, respectively for changing rule between differential pressure and time of the pre-filter and efficient filter. For the same geographical area, and the local air dust content is relatively stable, the operation time can be thought a linear relationship with system clogging capacity.

Figure 3 shows the corresponding relation between the air filter flow rate of filter element and differential pressure. Some related research [21] conclusions indicate that the filter resistance has the following corresponding relations with filtering system flow:

$\Delta \mathrm{P}=\mathrm{av}+\mathrm{bv}^{2}$

Among them, $\Delta \mathrm{P}$ for filter differential pressure, $\mathrm{v}$ for filter windward side speed, $\mathrm{a}$ and $\mathrm{b}$ for the test coefficient provided by the manufacturing unit. On the assumption that intake filter units intake air uniformly, and all of the filters in each level have specification consistent, the corresponding relationship between differential pressure and filtering system flow can be expressed by formula (8). Respectively select differential pressure and filtering system flow when the pre-filter and efficient filter meet the design using differential pressure, as a filter differential pressure - flow characteristic curve. The relationship between differential pressure and the inlet flow of pre-filter and efficient filter is shown in figure 3.

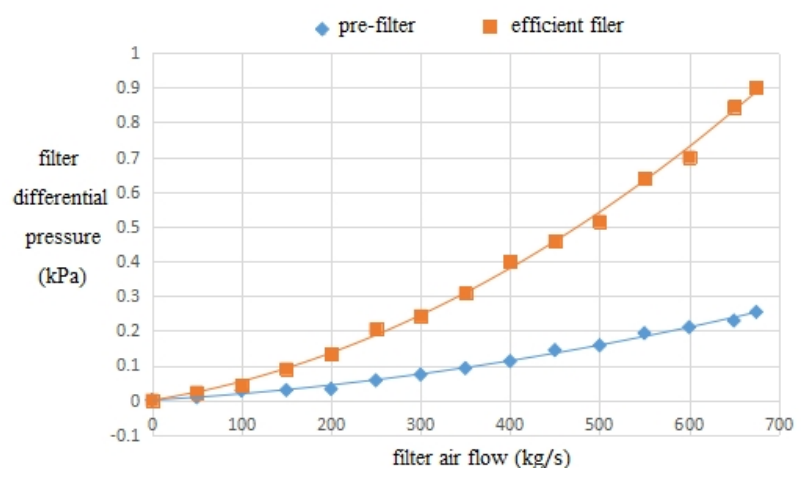

Fig.3 The relation between the differential pressure and the air flow of the pre-filter and the efficient filter

By fitting to get the relationship between differential pressure and air flow of coarse filter and efficient filter showing as follows:

$$
\begin{aligned}
& P_{p-q}=1.4 \times 10^{-4} q+3.5 \times 10^{-7} q^{2} \quad(0 \leq q \leq 675) \\
& P_{e-q}=3.9 \times 10^{-4} q+1.4 \times 10^{-6} q^{2} \quad(0 \leq q \leq 675)
\end{aligned}
$$

Among them, $\mathrm{P}_{\mathrm{p}-\mathrm{q}}$ and $\mathrm{P}_{\mathrm{e}-\mathrm{q}}$ respectively for differential pressure of pre-filter and efficient filter , unit $\mathrm{kPa}$, q for filter air flow, unit $\mathrm{kg} / \mathrm{s}$.

\section{LCC calculation of air intake system}

Gas turbine inlet system life cycle is usually equal to gas turbine ontology life cycle. Since the first bidding bid in 2004, gas turbine ontology localization has obvious progress. As to air intake system, AAF, Camfil, Donaldson and other gas turbine inlet system manufacturers also respectively set joint venture in domestic. To a certain extent the domestic market has formed. But the air intake system is usually simultaneously purchase with gas turbine noumenon, and for domestic gas turbine filter testing has some deficiencies, such as filter suppliers add the electrostatic before testing filter material to improve filtering level [17], and lack of guidance of gas turbine cost in the life cycle, to a certain it objectively forms he common situation of low bid in the process of air intake system procurement.

Due to the large initial investment of air intake system, non-benefits, and lacking of domestic related research, the air intake system LCC related research is lag behind. At the same time, due to the funds shortage in the enterprises and lacking of intuitive understanding for the equipment operation maintenance cost in the late period, it caused the enterprise often go to the dilemma between the lower 
initial investment and reducing running maintenance cost when carries on the equipment type selection.

On the basis of air intake system LCC model, analyze an air intake system running data, respectively get characteristics between differential pressure and air flow, characteristics between differential pressure and running time, then optimize the air intake system. Under the premise of unchanging the basic configuration of existing air intake system and precision of all levels, by increasing the filtration system unit number, considering the various factors which influent the air intake system cost, adopt the net present value (NPV) method to discount life period cost, and find out the main factors influencing the air intake system LCC to realize the elaborating management costs. Choose the filter number as the optimize parameter, and import the capacity expansion coefficient $\mathrm{k}$. Assume that the optimized filter number is $\mathrm{k}$ times for the original design $(\mathrm{k}>1)$, the costs before and after optimization are as follows.

Acquisition cost $\mathrm{C}_{\mathrm{aq}}$

In acquisition cost $\mathrm{C}_{\mathrm{aq}}$, as the part $\mathrm{C}_{\mathrm{st}}$ due to the filter group number increasing, the corresponding air intake stents and intake filter room costs will increase. $\mathrm{C}_{\mathrm{f}}$ and the initial set of filter can be regarded as the direct relations. Both cost before and after optimization are shown in table 1.

Tab. $1 \mathrm{C}_{\mathrm{aq}}$ of filtration system

\begin{tabular}{ccc}
\hline $\mathrm{C}_{\mathrm{aq}}$ & $\mathrm{C}_{\mathrm{st}}$ (ten thousand Yuan) & $\mathrm{C}_{\mathrm{ft}}$ (ten thousand Yuan) \\
\hline Initial design & 1680 & 300 \\
After optimization & $540+1140 \mathrm{k}$ & $300 \mathrm{k}$ \\
\hline
\end{tabular}

Ownership cost Cow

Based on the ownership cost Cow, the operating costs need to consider extra cost caused by the equipment heat consumption rate rising due to compressor fouling. Melissa Wilcox proved that the cost because of unit heat consumption rate change is the single value function with average heat consumption rate change during operation time [12]. Because in the current water strategy, water washing intervals are $300 \mathrm{~h}$, at the same time the air intake system optimization does not involve the filter filtration level change, then the compressor fouling rate keep the same before and after optimization. That's to say, the fee difference caused can be thought 0 .

Another part of the cost $\mathrm{Cch}$ and $\mathrm{Cma}$ are related with the specific operation mode of gas turbine. Cma is mainly all kinds of costs caused by filter replacement process produce. The pre-filter replacement cost is 20000 Yuan each time, and efficient filter is 100000 Yuan each time. Moreover, the filter element needs to be sampling inspected in the filter replace process, and the pre-filter and efficient filter sampling inspected fee are respectively 5000 Yuan and 25000 Yuan each time.

For the Cch, because the whole filter is k times of the original filter, and the total air flow rate through the filtration system remains the same, then the air flow through each filter unit correspondingly becomes $1 / \mathrm{k}$ times of the original, which causes the cartridge characteristics between time and differential pressure changing, and the parameters need to be refactoring.

The service life growth of filtering unit is the result of superposition of two effects in the optimization: (1) the amount of air flow through the filtration system is the same, while each filter unit air capacity is only equivalent to $1 / \mathrm{k}$ of the original. According to the feature between time and differential pressure of filtration unit, to reach the original clogging capacity, the needed filter time is $\mathrm{k}$ times of the original. (2) under the condition of reaching the original clogging capacity, due to the air flow of a single filtration unit reducing, according to the formula (1) and (11), the relationship between differential pressure and air flow of filtering system is as follows.

$$
\begin{aligned}
& P_{p-q}^{k}=1.4 \times 10^{-4}\left(\frac{q}{k}\right)+3.5 \times 10^{-7}\left(\frac{q}{k}\right)^{2} \quad(0 \leq q \leq 675) \\
& P_{e-q}^{k}=3.9 \times 10^{-4}\left(\frac{q}{k}\right)+1.4 \times 10^{-6}\left(\frac{q}{k}\right)^{2} \quad(0 \leq q \leq 675)
\end{aligned}
$$

Under the condition of the constant air flow of intake system, make: 


$$
\frac{\mathrm{P}_{\mathrm{p}-\mathrm{q}}}{\mathrm{P}_{\mathrm{p}-\mathrm{q}}^{\mathrm{k}}}=\mathrm{m}_{1}, \frac{\mathrm{P}_{\mathrm{e}-\mathrm{q}}}{\mathrm{P}_{\mathrm{e}-\mathrm{q}}^{\mathrm{k}}}=\mathrm{m}_{2}
$$

Then the corresponding service lives of the pre-filter and efficient filter ( $\mathrm{Hp}$ and $\mathrm{He}$ ) respectively are:

$$
\mathrm{H}_{\mathrm{p}}=2300 \times \mathrm{k} \times \mathrm{m}_{1}, \quad \mathrm{H}_{\mathrm{e}}=7200 \times \mathrm{k} \times \mathrm{m}_{2}
$$

Assume the power plant design life is 30 years, the annual operation hours is $\mathrm{T}$, and the operation cost allocates for the year cost, make:

$$
\mathrm{n}_{1}=\frac{\mathrm{T}}{\mathrm{H}_{\mathrm{p}}}, \mathrm{n}_{2}=\frac{\mathrm{T}}{\mathrm{H}_{\mathrm{e}}}
$$

Then $\mathrm{C}_{\mathrm{ch}}$ and $\mathrm{C}_{\mathrm{ma}}$ before and after optimization are shown in table 2.

Tab.2 Cow of filter stages per year

\begin{tabular}{ccc}
\hline Cow & Cch (ten thousand Yuan per year) & Cma (ten thousand Yuan per year) \\
\hline Coarse filter & $25 \mathrm{n} 1$ & $2.5 \mathrm{n} 1$ \\
Efficient filter & $2758 \mathrm{n} 2$ & $12.5 \mathrm{n} 2$ \\
\hline
\end{tabular}

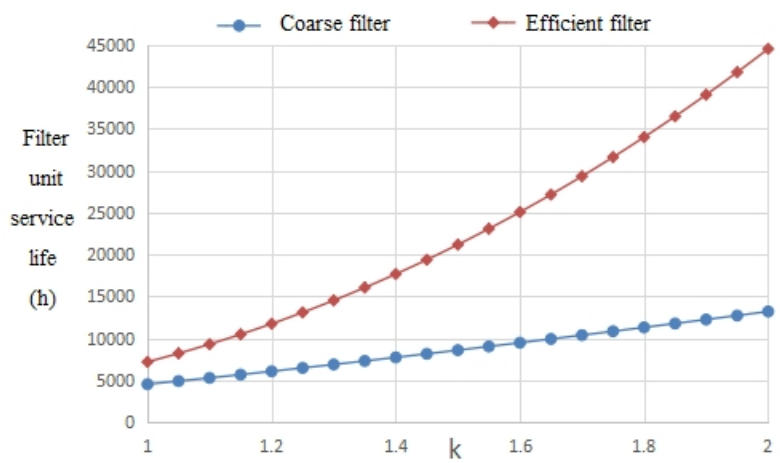

Fig.4 Curve of each filter stage differential pressure changing with ratio $\mathrm{k}$

The disposal cost Cdi

The disposal cost of air intake system is directly related with the local environmental protection policy and waste composition. With the current environmental protection policy, the scrap value of air intake system structure is almost the same as the equipment labor expense, handing expense of filtration unit and filter piping system, so it can be thought that Cdi is equal to Csv, which is zero.

\section{The LCC optimization of air intake system}

Analyze the net present value of air intake system, choosing the discount rate international commonly used (10\%), under the premise of no inflation, air intake system NPV is as follows:

$$
\mathrm{NPV}_{\mathrm{b}}=\left(\mathrm{C}_{\mathrm{st}}+\mathrm{C}_{\mathrm{ft}}\right)+\left(\mathrm{C}_{\mathrm{ch}}+\mathrm{C}_{\mathrm{ma}}\right) \sum_{\mathrm{i}=1}^{30}(1+0.1)^{\mathrm{i}}
$$

Under the different $\mathrm{k}$ value, the power plant operation hours is from $2500 \mathrm{~h}$ to $6500 \mathrm{~h}$, then the $\mathrm{NPVb}$ of air intake system in the whole life cycle is as shown in figure 5:

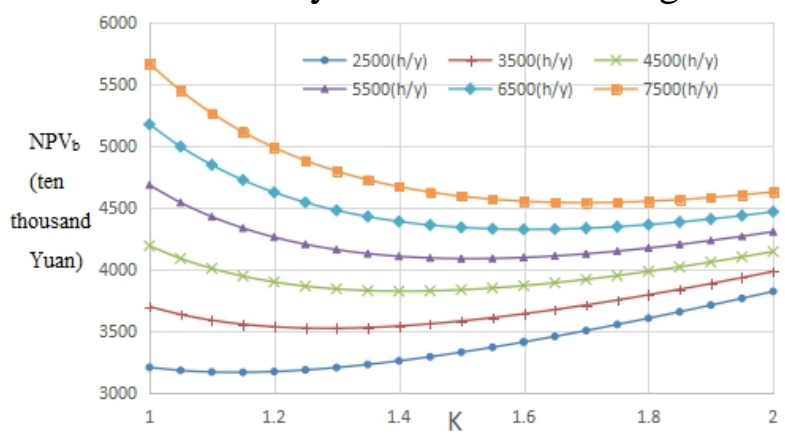

Fig.5 The relationship of between $\mathrm{NPV}_{\mathrm{b}}$ and ratio $\mathrm{k}$ at different running hours per year

It is not hard to see from figure 5 that: (1) For a set of air intake system, there is a particular $k$ value to make the lowest NPV value of air intake system. The relationship shows that the higher the initial 
investment, the lower the corresponding filter replacement and maintenance frequency, which has lower cost. That's to say, there is an optimal relationship between them. (2) In the case of different annual operating hours, the corresponding $\mathrm{k}$ value is different. For lower running hours in peak shaving plant, $\mathrm{k}$ value is close to 1 . The calculations show that the annual operation hours which is less than $1650 \mathrm{~h}$ of power plant, the NPV is monotone increasing function of $\mathrm{k}$. In the annual operating hours for $6500 \mathrm{~h}$ of heating power plant, the NPV is lowest when $\mathrm{k}=1.7$. At the same time, the replacement cycles of pre-filtration unit and efficient filtration unit are respectively $14000 \mathrm{~h}$ and $23000 \mathrm{~h}$. It can guarantee the reliability of continuous heating and reduce the pressure difference abnormal growth caused by short-term climate change leading to unplanned downtime or reduced output operation.

Take a certain power plant with annual operation hour $4500 \mathrm{~h}$ and unit design life 30 years for example. A gas turbine filter system costs are shown in figure 6. Equipment acquisition cost Caq is 19.8 million Yuan, the annual maintenance cost Cma is 2.3349 million Yuan, the NPV value after discounting is 41.8111 million Yuan. After the air intake system importing the optimization factor $\mathrm{k}$ (1.4), the acquisition cost Caq is 25.56 million Yuan,the annual maintenance cost Cma is 1.3466 million Yuan, the NPV value after discounting is 38.2445 million. From the optimization effect it's not hard to see that importing optimization factor $\mathrm{k}$, although the initial investment raising 5.76 million Yuan, the maintenance costs save 0.9883 million Yuan per year at the same time. On the perspective of air intake system whole life cycle, the optimized scheme is more economical.

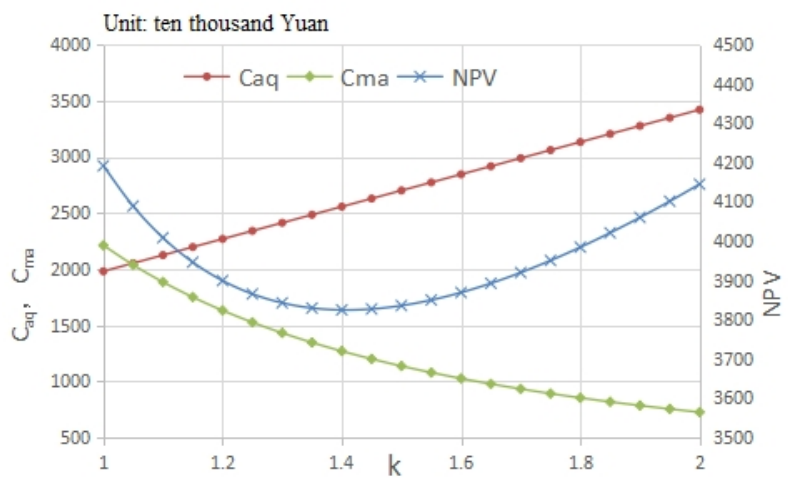

Fig.6 The relationship between NPV and sub-cost of intake system with ratio $\mathrm{k}$

\section{Conclusion}

1) According to the air intake system LCC theory this paper proposes a new cost optimal method based on the whole life cycle cost of air intake system. By reasonably increasing the filter unit number, expanding the air intake system capacity, the filter unit replacement cycle extends and the unit reliability improves, at the same time, the air intake system running maintenance cost reduces and the NPV keeps lowest throughout the life cycle.

2) Analyze the filtering unit usage situation of a power plant air intake system, establish the filter unit model between time and differential pressure together with the filter unit model between air flow and differential pressure. Propose the filtering system optimization coefficient $\mathrm{k}$, and analyze the best $\mathrm{k}$ value choice under different annual operation hours.

3) Take a power plant for example. The plant annual operation hours is $4500 \mathrm{~h}$, the corresponding optimization coefficient $\mathrm{k}$ is 1.4. In this case, although the air intake system acquisition cost raises 5.76 million Yuan, the operation and maintenance cost of air intake system can save 0.9883 million Yuan every year. The service lives of pre-filter and efficient filter respectively rise from $2300 \mathrm{~h}$ and $7200 \mathrm{~h}$ to $7700 \mathrm{~h}$ and $17700 \mathrm{~h}$. And for the long-term stable operation heating unit, the equipment reliability is greatly improved. 


\section{References}

[1] Zwebek A I, Pilidis P. Degradation effects on combined cycle power plant performance part 3 : gas and steam turbine degradation effects[C]//Proceedings of the ASME Turbo Expo. Amsterdam, Netherlands: ASME, 2002:763-770.

[2] ZhangYing,WangWenlin.Introduction of Air Intake System for Siemens SGT5-4000F Gas Turbines. [J] Thermal Turbine, 2009, (38)2: 122-125.

[3] Anoop Kumar Shukla,Onkar Singh.Effect of Compressor Inlet temperature\&Relative Humidity on Gas turbine cycle performance[C].International Journal of Scientific \& Engineering Research, Volume 5, Issue 5, May-2014,664-671.

[4] Melissa Wilcox,Rainer Kurz,Klaus Brun1.Technology Review of Modern Gas Turbine Inlet Filtration Systems[J].The international journal of rotating machinery,2012(12):1-15.

[5] Xie Yajun.Modification of Gas Turbine Intake Filter System[J].Water Conservancy \& Electric Power Machinery,2013, (35)7:64-65.

[6] Chen Jianhong,Cheng Yuan,ShengDeren,et al.Research on Update Interval Optimization Strategy Model of Gas Turbine Filtration.Proceedings of the CSEE,2014,34（20）:3302-3307.

[7] Cheng Yuan,Chen Jianhong,ShengDeren,et al.Research on Washing Strategy Optimization Model of Combined Cycle Gas Turbines. Proceedings of the CSEE,2013,33（26） : 95-100.

[8] Yang Jiaji.Research on Economical Replacement Cycle of Gas Turbine Air Filters.Power Equipment, 2012, 26(6): 407-409.

[9] Zhu Jinjie.Study on Anti - fogging Technology of Gas Turbine Intake System[J].Water Conservancy \& Electric Power Machinery, 2015,(37)7:62-64.

[10] Debabrata Lahiri,Gokul Acharjee.Life Cycle Cost of Electricity Generation from Biomass Gasifier[J]. Journal of Energy and Power Engineering 7 (2013): 2060-2067.

[11] Frank W. Muscrof.Filter life cycle costing for gas turbines [M].1995.

[12] Wilcox M. Gas turbine inlet filtration system life cycle cost analysis[C]//Proceedings of the ASME Turbo Expo., Vancouver, Canada: ASME, 2011: 675-682.

[13] Pamela L.Spath.Margaret K.Mann.Life Cycle Assessment of a Natural Gas Combined-Cycle Power Generation System[M].US,National Renewable Energy Laboratory,2000:1-2.

[14] MaXiaojiu,ShiFeng,LiuPengwei,et al.Introduction and Using Analysis of Life Cycle Cost Management[J]. HeNan Electric Power, 2006(4):18-21.

[15] ZhangJun.Decision Analysis of Substation Construction Based on Life Cycle Cost (LCC)[D]. ChongQing: ChongQing University, 2007.

[16] CuiXinqi,YinLaibin,FanChunju,et al.Study of LCC for power transformer in modiflcation of transforuler substation[J].Power System Protection and Control, 2010,V38(7):69-73.

[17] Sun Lixue,Hao Hongliang,Zhang Tao,et al. Introduction of the Inlet Air Filtration Standard and Inspector Methords of Gas Turbine.

[18] Tae Won SONG, Jeong Lak SOHN,Tong Seop KIM.AnImproved Analytic Model to Predict Fouling Phenomena in the Axial Compressor of Gas Turbine Engines[C].Proceedings of the International Gas Turbine Congress, 2003 ,Tokyo:1-7.

[19] Cyrus B. Meher-Homji,Andrew Bromley.Gas turbine axial compressor fouling and washing[C]. Proceedings of the Thirty-Third Turbomachinery Symposium. 2002, 163 191. 
[20] Wilcox M. Gas turbine inlet filtration system life cycle cost analysis[C]//Proceedings of the ASME Turbo Expo, Vancouver, Canada: ASME, 2011:675-682.

[21] Wang Chun,Zhang Dianyin.Handbook on Dust Removal Engineering Technology[M].BeiJing: Chemical Industry Press,2016: 652-653. 